\section{Epi 04}

EPIRUBICIN IN ADVANCED GASTROTNTESTINAL (GI) CANCER Wils JA, Laurentius Hospital, $6043 \mathrm{CV}$ Roermond, NL EPIRUBICIN (E) is one of a series of new anthracycline antibiotics synthesized in an attempt to identify agents with a superior therapeutic index to the parent compound doxorubicin (DX). The acute and chronic toxicity of $\mathrm{E}$ is less than of DX in equirolar doses. GI cancer is generally considered as a chemotherapy resistant tumour and in this disease equitoxic doses of $\mathrm{E}$ compared with $\mathrm{DX}$ could be of interest. In locally advanced oesofageal cancer $\mathrm{E}$ has been combined with radiotherapy $(3.400-3.800 \mathrm{~Gy})$. E in a daily dose of $50 \mathrm{mg} / \mathrm{m}^{2}$ days $1,2,22,23$. Out of 17 evaluable patients 6 complete and 7 partial responses were achieved, with a median duration of $6+$ months. In advanced gastric carcinoma 5-fluorouracil (5-FU) and adriamycin (A) have definite activity. Used as a single agent $E$ showed a response in 4 out of 15 patients. E was given in a dose of $50 \mathrm{mg} / \mathrm{m}^{2}$ day 1 and day 2 , every 3 weeks. In a randomized trial comparing 5-FU vs. 5-FU and $\mathrm{E}$, the combination showed a significantly higher response rate (41\%) than 5-FU alone (20\%). In this study that included 62 evaluable patients, $E$ was given in a dose of $40 \mathrm{mg} / \mathrm{m}^{2}$ day 1 and 2 . The median duration of remission was 8 months in the combination group. In advanced pancreatic carcinoma the EORTC GI group has conducted a phase II trial using $E$ as single drug in a dose of $90 \mathrm{mg} / \mathrm{m}^{2}$ day 1 every 4 weeks with dose escalation. Out of 30 fully evaluable patients 8 resporses were noted. Toxicity was slight with a median nadir of white cells of $2.7 \times 10^{9} / \mathrm{L}$. Median duration of response was 7 months. In colorectal carcinoma the most clinical trials with $E$ have been performed. There has emerged a difference in activity between colon and rectosigmoid carcinoma which is not clearly understood. In colorectal carcinona 26 responses (9\%) in 300 patients have been reported in compilated series. In rectosigmoid carcinoma response rate was 13\%, and in previously untreated patients $24 \%$. It is concluded that $E$ appears to have activity in GI cancer, esp. in gastric and pancreatic cancer.

\section{Epi 05}

PDLYCHEMOTHERAPY OF ADVANCED SOFT TISSUE SARCOMAS WITH $4^{\circ}$-EFIDOXORUBICIN (4'-EFI-DX) AND CISPLATIN (DDP) H.Sauer, H.hair, U.Fink, H. Rückle, H.Schulz, W. Hileanns

CYvaDic polychenotherapy is the nost used regimen for the treatment of locally advanced or metastasized soft tissue sarconas. Reaission rates are between $15 \%$ and $50 \%$, but reaission durations are short. Therefore a nore aggressive regieen with dose escalation was studied.

TREATHENT PLAH: 4-EPI-DX $45 \mathrm{~g} / \mathrm{q}$ i.v days $1+2$, DDP 90 ag/qa i.v. day 2 every 3-4 weeks; dose escalation of 5 g/qa for each dose of $4^{\circ}$-EPI-DX if leukocyte nadir 22000/que and platelet nadir \$70806/que.

RESULTS: 27 pat had 108 treatment cycles. In 34 (427) of the 81 second and following cycles 4 *-Epi-bX was escalated. 1 pat was not evaluable for response because of early death (tumor related) after the first cycle. of the $2 b$ evaluable pat 4 (15z) had complete remission (CR: eedian duration $6+-0), 6(232)$ had partial reaission (PA: $3.5+$ no) $12(46 x)$ had stable disease after previous progression (MC: 4.5 ol, 4(157) had pricary progressive disease (PD). It could not be established that pat with dose escalation had better response. Pat with CR were 2 leiomysarcoma, 1 liposarcona, 1 synovial sarcoma; 2 CR confirmed by clinical records, 2 by second look operations.

TOXICITY: heatologic toxicity, alopecia, nausea and voniting were seen in all pat. 4 pat refused further treatuent because of severe voniting. 4 pat had neurotoxicity grade $1-3,2$ pat ototoxicity garde $2-3$ why treatment was stopped in 1, 1 pat had possibly cardionyopathy why treatent was stopped afetr 10 cycles.

SUHAARY: 4*-EPI-DX+DDF is effective in the palliative treatment of advanced soft tissue sarcomas. the objective response rate is $38 x$, but the response duration is rather short. So, the results are siailar to crvadic treatment. Toxicity is sonetiaes treatent lieiting.

Med.Klinik III, LWU München, Harchioninistr.15, D-Beng München 7b; Med.Klinik I, TU Hünchen; Hed.Poliklinik Mürzburg.

\section{Int 01}

LOW-DOSE HUMAN RECOMBINANT INTERFERON $-\alpha-2 C$ ARG $(\mathrm{Hu}-r$ IFN $-\alpha$ ) IN HAIRY CETI-LEJKEMIA ( HCL) DESIGN, RECRUITMENT AND FIRST OBSERVATIONS IN A PROSPECTIVE RANDOMIZED MULTICENTER TRIAL H.Pralle, B.Dörken, R.M.Parwaresch, T.Zwingers, K.Bross, H. Gamm, S. Bödewadt, H. Bartels, M. Böger, K. Bremer, H. Ermrich, H.Euler, T.Fischer, H.Fuhr, A.Ganser, B.Goldmann, J. Hartlapp, J. Hayungs, A.D. Ho, K. Kabelitz, J. Kraft, E.U.Mïller, A.Neubauer, L.Nowicki, K.Pflüger, H.Schmidt, W. Schmidt and U. Papendick.

Class one IFNs ( $x$ and $B$ ) are active in HCL. The efficacy of Hu-rIFN $\alpha-2 c$ in HCL at 5.10 IU or higher doses has also been proven. Although response to IFN occurs nearly without exception the underlying mechanisms have not yet been elucidated, nor the minimal required doses for induction and maintenance therapy. Treatment modalities for recurrent disease will soon be needed. They should be derived from the experiences of larger studies.

During a 12 months period 31 institutions entered 72 patients onto a protocel for low-dose IFN in HCL. 3 were excluded by the histopathologic reviewers. Recruitment increased steadily over the observed time 59 patients received $2 \cdot 10^{6}$ IJ $\mathrm{Hu}-r$ IFN $\alpha-2 \operatorname{carg}\left(\right.$ Berofor ${ }^{\mathrm{R}}$ ) s.c. daily for at least 28 days. Patients entering beyond july 1984 were randomized after 84 days of treatment, if they reached stage $A$ or I according to Jansen either to receive maintenance or to stop therapy. IFN will be reinstituted whenever stage A/I will be lost. Occurrence of camplete remissions, total required doses to maintain $\mathrm{A} / \mathrm{I}$-stage, and emergence of antibodies to IFN will be evaluated for both treatment arms.

20 patients entered the protocol prior to splenectomy. No complications occurred so far. 5 out of 35 splenectomized patients died due to deteriorating infections (4) or CNSbleeding (1). These deaths prompted us, to try further dose reduction. In 2 out of $52 \cdot 10^{5}$ IU IFN worked so far, 3 patients are tooearly for evaluation.

Medizinische Klinik, Klinikstraße 36, D-6300 GIESSEN

Int 02

MINIMAL, NEOPTERIN-GUIDED DOSES OF ALPHA INTERFERON ARE CLINICALLY EFFECTIVE AND ATOXIC IN HAIRY CELL LEUKEMIA W.Aulitzky, G.Gast1, H.Tilg, J.Troppmair, R.Flener, C.Huber

Hairy cell leukemia has been shown to be extraordinary sensitive to treatment with alpha-Interferon. Therefore it represents a unique model for studying the efficacy of various dose regimens. We present the results of a phase II trial with two different dose schedules of alpha IFN. Firstly a conventional dose schedule, and secondly, a biologically defined dose regimen: We tried to define clinically effective Interferon doses by assessment of a biochemical marker. Neopterin, the marker molecule chosen, is a stable GIP-degradation product, wich is produced in Macrophages. The key enzyme of this metabolic pathway, a GTP-cyclohydrolase is regulated by interferons in an dosedependent manner (J.Exp.Med 160:310-316). Thus the neopterin level in serum and urine reflects the local interferon concentration in the tissue. Eleven patients were entered in the study. In the first group, six patients were treated with conventional doses of rhu-IFN-alpha 2 $\left(3 \times 10^{6} / \mathrm{m}^{2} / \mathrm{d}\right.$ s.c.). In the second group ( $5 \mathrm{pts}$ ) individual dose finding was performed at the beginning of IFN-therapy IFN was administered subcutanously beginning with $1 \times 10^{5} \mathrm{U}$ per day and then increased by $1 \times 10^{5}$ q.d.s. for two weeks. In parallel neopterin excretion in the urine was assessed daily by radioimmunoassay. The minimal IFN dose wich induced maximum neopterin excretion was chosep for further treatment. IFN doses in the order of $5-7 \times 10^{5} \mathrm{U} / \mathrm{d}$ proved to be sufficient for triggering maximum neopterin excretion in the urine.After one year of Interferon treatment all patients were evaluable. At this time both dose regimens proved to be effective in terms of their antileukemic activity, but differed significantly in toxicity. Side effects were only seen in patients who received "conventional" doses.

Abtlg f. Klin. Immunbiologie, Univ. Klinik f. Innere Medizin, A-6020 Tnnsbruck, Anichstr. 35 